Article

\title{
Hospital-Acquired Serum Ionized Calcium Derangements and Their Associations with In-Hospital Mortality
}

\author{
Charat Thongprayoon ${ }^{1, *}$, Panupong Hansrivijit ${ }^{2}{ }^{(0)}$, Tananchai Petnak ${ }^{3,4}$, Michael A. Mao ${ }^{5}(\mathbb{D}$, \\ Tarun Bathini $^{6}$, Saraschandra Vallabhajosyula ${ }^{7}$ D, Ploypin Lertjitbanjong ${ }^{8}$, Fawad Qureshi ${ }^{1}$, \\ Stephen B. Erickson ${ }^{1}$ and Wisit Cheungpasitporn ${ }^{1, * \mathbb{D}}$ \\ 1 Division of Nephrology and Hypertension, Department of Medicine, Mayo Clinic, \\ Rochester, MN 55905, USA; Qureshi.Fawad@mayo.edu (F.Q.); Erickson.Stephen@mayo.edu (S.B.E.) \\ 2 Department of Internal Medicine, University of Pittsburgh Medical Center Pinnacle, \\ Harrisburg, PA 17101, USA; hansrivijitp@upmc.edu \\ 3 Division of Pulmonary and Pulmonary Critical Care Medicine, Faculty of Medicine, Ramathibodi Hospital, \\ Mahidol University, Bangkok 10400, Thailand; petnak@yahoo.com \\ 4 Division of Pulmonary and Critical Care Medicine, Department of Medicine, Mayo Clinic, \\ Rochester, MN 55905, USA \\ 5 Division of Nephrology and Hypertension, Mayo Clinic, Jacksonville, FL 32224, USA; \\ mao.michael@mayo.edu \\ 6 Department of Internal Medicine, University of Arizona, Tucson, AZ 85721, USA; tarunjacobb@gmail.com \\ 7 Section of Interventional Cardiology, Division of Cardiovascular Medicine, Department of Medicine, \\ Emory University School of Medicine, Atlanta, GA 30322, USA; saraschandra21@gmail.com \\ 8 Division of Pulmonary, Critical Care and Sleep Medicine, University of Tennessee Health Science Center, \\ Memphis, TN 38163, USA; ploypinlert@gmail.com \\ * Correspondence: charat.thongprayoon@gmail.com (C.T.); wcheungpasitporn@gmail.com (W.C.)
}

Received: 18 October 2020; Accepted: 17 November 2020; Published: 19 November 2020

\begin{abstract}
Background: The objective of this study was to report the incidence of in-hospital serum ionized calcium derangement and its impact on mortality. Methods: We included 12,599 nondialytic adult patients hospitalized at a tertiary medical center from January 2009 to December 2013 with normal serum ionized calcium at admission and at least 2 in-hospital serum ionized calcium values. Using serum ionized calcium of $4.60-5.40 \mathrm{mg} / \mathrm{dL}$ as the normal reference range, in-hospital serum ionized calcium levels were categorized based on the presence of hypocalcemia and hypercalcemia in hospital. We performed logistic regression to assess the relationship of in-hospital serum ionized calcium derangement with mortality. Results: Fifty-four percent of patients developed new serum ionized calcium derangements: $42 \%$ had in-hospital hypocalcemia only, $4 \%$ had in-hospital hypercalcemia only, and $8 \%$ had both in-hospital hypocalcemia and hypercalcemia. In-hospital hypocalcemia only (OR 1.28; 95\% CI 1.01-1.64), in-hospital hypercalcemia only (OR 1.64; 95\% CI 1.02-2.68), and both in-hospital hypocalcemia and hypercalcemia (OR 1.73; 95\% CI 1.14-2.62) were all significantly associated with increased in-hospital mortality, compared with persistently normal serum ionized calcium levels. Conclusions: In-hospital serum ionized calcium derangements affect more than half of hospitalized patients and are associated with increased in-hospital mortality.
\end{abstract}

Keywords: hypercalcemia; hypocalcemia; calcium; electrolytes; mortality; hospitalization

\section{Introduction}

Calcium is an important cation in the human body that plays a significant role in maintaining cellular biologic function, either in the free ion or protein-bound complexes $[1,2]$. The majority $(>99 \%)$ 
of total body calcium resides in the bones as hydroxyapatite, a form of calcium-phosphate complex [3]. The remaining total body calcium (approximately 10 in adults) exists outside of the skeletal system and participates in a myriad of essential functions, including neurotransmitter release, muscle contraction, and cellular signaling. Approximately 50\% of circulating calcium ions are bound to protein, such as albumin or globulin, whereas the rest exists as unbound ionized (free) calcium [4-8]. Measuring ionized calcium is important, as Payne's formula [6] for corrected total calcium level tends to overestimate ionized calcium, especially in patients with hypoalbuminemia $[7,8]$. Thus, the gold standard for evaluating calcium status is to measure ionized calcium $[9,10]$.

Disturbances of serum calcium, hypocalcemia and hypercalcemia, are associated with increased mortality [11-17]. A large retrospective cohort study of the United States Department of Veterans Affairs involving 1.9 million patients suggested a U-shaped association between calcium disturbances and mortality [18]. Furthermore, long-term effects of serum calcium derangements are also possible. Both reduced and elevated admission serum ionized calcium were associated with increased 1 year mortality with a U-shape relationship [19]. While the effects of calcium disturbances at hospital admission on poor outcomes among hospitalized patients have been demonstrated $[4,5,19]$, the incidence of in-hospital calcium disturbances and their association with mortality are currently unknown.

Therefore, the objective of this study was to investigate the incidence of in-hospital hypocalcemia and hypercalcemia, assessed by serum ionized calcium level, and their impact on in-hospital mortality among hospitalized patients.

\section{Materials and Methods}

\subsection{Study Population}

The Mayo Clinic Institutional Review Board approved this study and waived the need for informed consent as long as patients provided Minnesota research authorization, due to the minimal risk nature of this investigation.

We initially searched our institutional database to identify all patients (aged 18 years or older) who were admitted to Mayo Clinic Hospital, Rochester, Minnesota, from 2009 to 2013. Our inclusion criteria consisted of (1) patients who had normal admission serum ionized calcium levels of 4.60 to $5.40 \mathrm{mg} / \mathrm{dL}$, and (2) patients who had at least two in-hospital serum ionized calcium values. Exclusion criteria consisted of patients who required renal replacement therapy in hospital.

\subsection{Definition of In-Hospital Hypocalcemia and Hypercalcemia}

We reviewed all in-hospital serum ionized calcium values. All serum ionized calcium values were analyzed from venous blood samples collected in serum separating tubes or serum gel tubes using the ion-selective electrode method throughout the study period. Serum ionized calcium was adjusted to $\mathrm{pH} 7.40$ to account for changes in specimen $\mathrm{pH}$ that may occur during transport. We considered serum ionized calcium at $4.60-5.40 \mathrm{mg} / \mathrm{dL}$ as the normal range according to our hospital's laboratory reference values [20]. We identified in-hospital hypocalcemia as having any in-hospital serum ionized calcium values $<4.60 \mathrm{mg} / \mathrm{dL}$ and in-hospital hypercalcemia as having any in-hospital serum ionized calcium values $>5.40 \mathrm{mg} / \mathrm{dL}$. In-hospital serum ionized calcium levels were classified into 4 categories based on the occurrence of in-hospital hypocalcemia and hypercalcemia: (1) persistently normal serum ionized calcium, (2) in-hospital hypocalcemia only, (3) in-hospital hypercalcemia only, and (4) both in-hospital hypocalcemia and hypercalcemia.

\subsection{Outcomes}

We assessed the impact of in-hospital serum ionized calcium derangements on in-hospital mortality. We used the institutional database to determine vital status at hospital discharge. 


\subsection{Statistical Analysis}

We tested the normality of continuous variables using the Shapiro-Wilk test. We presented continuous variables as mean \pm standard deviation (SD) for normally distributed data, or median (interquartile rate (IQR)) for skewed data. We compared continuous variables using analysis of variance for normally-distributed data, or the Kruskal-Wallis test for skewed data. We presented categorical variables as frequency (percentage) and compared them using the chi-squared test. We obtained the mortality's odds ratio (OR) for in-hospital serum ionized calcium derangements, compared with the persistently normal serum ionized calcium group, using logistic regression analysis. We adjusted OR for age, sex, race, principal diagnoses, comorbidities, estimated glomerular filtration rate, acute kidney injury, kidney replacement therapy, intensive care unit admissions, the number of in-hospital serum ionized calcium measurements, length of hospital stay, and admission serum ionized calcium. We considered a two-tailed p-value less than 0.05 as statistically significant. We performed all analyses using JMP statistical software (Version 10; SAS Institute Inc., Cary, NC, USA).

\section{Results}

\subsection{Incidence of In-Hospital Hypocalcemia and Hypercalcemia}

Figure 1 showed the study selection process. A total of 12,599 hospitalized patients were eligible for the analysis. The median number of in-hospital serum ionized calcium measurements was three (two to five). Among all patients, 6402 (51\%) and 1544 (12\%) developed new in-hospital hypocalcemia and hypercalcemia, respectively. Five thousand seven hundred and thirty-nine (46\%) had persistently normal serum ionized calcium throughout the hospital stay, $5316(42 \%)$ had in-hospital hypocalcemia only, $458(4 \%)$ had in-hospital hypercalcemia only, and 1086 (8\%) had both in-hospital hypocalcemia and hypercalcemia. Table 1 demonstrated clinical characteristics according to in-hospital serum ionized calcium groups.

The incidence of both in-hospital hypocalcemia and hypercalcemia was associated with younger age, female, non-Caucasian, admission for cardiovascular diseases, occurrence of acute kidney injury, need for ICU admission, greater number of serum ionized calcium measurements, and a longer length of hospital stay.

\subsection{Association of In-Hospital Hypocalcemia and Hypercalcemia with Mortality}

Mortality occurred in $3.1 \%$ of patients with in-hospital hypocalcemia, compared with $2.4 \%$ of patients without in-hospital hypocalcemia $(p=0.01)$. In-hospital hypocalcemia was significantly associated with increased in-hospital mortality, with an adjusted odds ratio of 1.29 (95\% CI 1.01-1.66; $p=0.04$ ) (Table 2).

The mortality occurred in $5.0 \%$ of patients with in-hospital hypercalcemia, compared with $2.4 \%$ in patients without in-hospital hypercalcemia. In-hospital hypercalcemia was significantly associated with increased in-hospital mortality with an adjusted odds ratio of 1.44 (95\% CI 1.06-1.95); $p=0.02)$ (Table 2).

The mortality was $2.7 \%$ in patients with in-hospital hypocalcemia only, $5.2 \%$ in patients with in-hospital hypercalcemia only, and $4.9 \%$ in patients with both in-hospital hypocalcemia and hypercalcemia, compared with $2.1 \%$ in patients with persistently normal serum ionized calcium throughout the hospitalization. The in-hospital hypocalcemia only, in-hospital hypercalcemia only, and both in-hospital hypocalcemia and hypercalcemia groups were all significantly associated with increased in-hospital mortality, compared with the persistently normal serum ionized calcium group, with adjusted odds ratios of 1.28 (95\% CI 1.01-1.64; $p=0.04), 1.64$ (95\% CI 1.02-2.68; $p=0.03), 1.73$ (95\% CI 1.14-2.62; $p=0.01$ ), respectively (Table 2 ). 
Table 1. Clinical characteristics of study patients.

\begin{tabular}{|c|c|c|c|c|c|c|}
\hline \multirow[b]{2}{*}{ Variables } & \multirow[b]{2}{*}{ All } & \multicolumn{5}{|c|}{ Serum Ionized Calcium during Hospitalization } \\
\hline & & Normal & Hypocalcemia Only & Hypercalcemia Only & $\begin{array}{l}\text { Both Hypo- and } \\
\text { Hypercalcemia }\end{array}$ & $p$-Value \\
\hline $\mathrm{N}$ & 12,599 & 5739 & 5316 & 458 & 1086 & \\
\hline Age (year) & $63 \pm 17$ & $63 \pm 17$ & $62 \pm 16$ & $66 \pm 16$ & $62 \pm 16$ & $<0.001$ \\
\hline Male sex & $7250(58)$ & $3181(55)$ & $3265(61)$ & $232(51)$ & $572(53)$ & $<0.001$ \\
\hline Caucasian & $11,584(92)$ & $5294(92)$ & $4902(92)$ & $425(93)$ & $963(89)$ & 0.001 \\
\hline \multicolumn{7}{|l|}{ Principal diagnosis } \\
\hline - Cardiovascular & $4281(34)$ & $1138(20)$ & $2321(44)$ & $141(31)$ & $681(63)$ & \\
\hline - Hematology/oncology & $2570(20)$ & $1363(24)$ & $1023(19)$ & $79(17)$ & $105(10)$ & \\
\hline - Infectious disease & $365(3)$ & $176(3)$ & $137(3)$ & $27(6)$ & $25(2)$ & \\
\hline - Endocrine/metabolic & $252(2)$ & $149(3)$ & $80(2)$ & $16(3)$ & $7(1)$ & \\
\hline - Respiratory & $548(4)$ & $346(6)$ & $151(3)$ & $28(6)$ & $23(2)$ & $<0.001$ \\
\hline - Gastrointestinal & $1041(8)$ & $611(11)$ & $338(6)$ & $46(10)$ & $46(4)$ & \\
\hline - Genitourinary & $271(2)$ & $156(3)$ & $81(2)$ & $22(5)$ & $12(1)$ & \\
\hline - Injury and poisoning & $1733(14)$ & $961(17)$ & $637(12)$ & $55(12)$ & $80(7)$ & \\
\hline - Other & $1538(12)$ & $839(15)$ & $548(10)$ & $44(10)$ & $107(10)$ & \\
\hline \multicolumn{7}{|l|}{ Comorbidity } \\
\hline - Coronary artery disease & $2940(23)$ & $1307(23)$ & $1241(23)$ & $127(28)$ & $265(24)$ & 0.08 \\
\hline - Congestive heart failure & $1057(8)$ & $443(8)$ & $444(8)$ & $46(10)$ & $124(11)$ & $<0.001$ \\
\hline - Peripheral artery disease & $555(4)$ & $265(5)$ & $211(4)$ & $28(6)$ & $51(5)$ & 0.09 \\
\hline - Stroke & $1032(8)$ & $498(9)$ & $376(7)$ & $46(10)$ & $112(10)$ & $<0.001$ \\
\hline - Diabetes mellitus & $2755(22)$ & $1333(23)$ & $1094(21)$ & $114(25)$ & $214(20)$ & 0.001 \\
\hline - COPD & $1383(11)$ & $672(12)$ & $525(10)$ & $65(14)$ & $121(11)$ & 0.002 \\
\hline - Cirrhosis & $287(2)$ & $127(2)$ & $113(2)$ & $12(3)$ & $35(3)$ & 0.15 \\
\hline Charlson Comorbidity Score & $2.0 \pm 2.4$ & $2.2 \pm 2.5$ & $1.8 \pm 2.3$ & $2.6 \pm 2.7$ & $1.6 \pm 2.0$ & $<0.001$ \\
\hline $\mathrm{eGFR}\left(\mathrm{ml} / \mathrm{min} / 1.73 \mathrm{~m}^{2}\right)$ & $77 \pm 28$ & $77 \pm 29$ & $77 \pm 26$ & $65 \pm 32$ & $76 \pm 25$ & $<0.001$ \\
\hline Acute kidney injury & $2611(21)$ & $869(15)$ & $1215(23)$ & $140(31)$ & $387(36)$ & $<0.001$ \\
\hline ICU admission & $8691(69)$ & $2947(51)$ & $4369(82)$ & $314(69)$ & $1061(98)$ & $<0.001$ \\
\hline $\begin{array}{l}\text { Number of serum ionized calcium } \\
\text { measurement in hospital }\end{array}$ & $3(2-5)$ & $2(2-3)$ & $4(3-6)$ & $4(3-7)$ & $5(4-9)$ & $<0.001$ \\
\hline Length of hospital stay (day) & $6(4-9)$ & $5(3-8)$ & $6(4-10)$ & $7(5-13)$ & $7(5-11)$ & $<0.001$ \\
\hline Admission serum ionized calcium (mg/dL) & $4.80(4.70-4.93)$ & $4.85(4.73-5.00)$ & $4.76(4.68-4.86)$ & $4.99(4.81-5.14)$ & $4.80(4.70-4.90)$ & $<0.001$ \\
\hline Lowest serum ionized calcium $(\mathrm{mg} / \mathrm{dL})$ & $4.57(4.23-4.75)$ & $4.75(4.66-4.85)$ & $4.28(4.04-4.45)$ & $4.85(4.70-5.01)$ & $4.11(3.94-4.30)$ & $<0.001$ \\
\hline Highest serum ionized calcium (mg/dL) & $4.98(4.82-5.20)$ & $4.97(4.85-5.10)$ & $4.90(4.77-5.09)$ & $5.60(5.46-5.81)$ & $5.73(5.54-6.20)$ & $<0.001$ \\
\hline
\end{tabular}

Continuous data are presented as mean \pm SD or median (IQR); categorical data are presented as count $(\%)$. 
Table 2. Association between in-hospital serum ionized calcium derangements and in-hospital mortality.

\begin{tabular}{|c|c|c|c|c|c|c|}
\hline \multirow{2}{*}{ Serum Ionized Calcium during Hospitalization } & \multirow{2}{*}{$\mathbf{N}$} & \multirow{2}{*}{ In-Hospital Mortality } & \multicolumn{2}{|c|}{ Univariable Analysis } & \multicolumn{2}{|c|}{ Multivariable Analysis } \\
\hline & & & OR $(95 \% \mathrm{CI})$ & $p$ & Adjusted OR (95\% CI) & $p$ \\
\hline \multicolumn{7}{|l|}{ In-hospital hypocalcemia } \\
\hline No & 6197 & $147(2.4)$ & 1 (ref) & - & 1 (ref) & - \\
\hline Yes & 6402 & $198(3.09)$ & $1.31(1.06-1.63)$ & 0.01 & $1.29(1.01-1.66)$ & 0.04 \\
\hline \multicolumn{7}{|l|}{ In-hospital hypercalcemia } \\
\hline No & 11,055 & $268(2.4)$ & 1 (ref) & - & 1 (ref) & - \\
\hline Yes & 1544 & $77(5.0)$ & $2.11(1.63-2.74)$ & $<0.001$ & $1.44(1.06-1.95)$ & 0.02 \\
\hline \multicolumn{7}{|l|}{ Groups } \\
\hline Normal & 5739 & $123(2.1)$ & 1 (ref) & - & 1 (ref) & - \\
\hline Hypocalcemia only & 5316 & $145(2.7)$ & $1.28(1.01-1.63)$ & 0.04 & $1.28(1.01-1.64)$ & 0.04 \\
\hline Hypercalcemia only & 458 & $24(5.2)$ & $2.52(1.61-3.95)$ & $<0.001$ & $1.64(1.02-2.68)$ & 0.03 \\
\hline Both hypo- and hypercalcemia & 1086 & $53(4.9)$ & $2.34(1.69-3.25)$ & $<0.001$ & $1.73(1.14-2.62)$ & 0.01 \\
\hline
\end{tabular}

Adjusted for age, sex, race, principal diagnosis, Charlson comorbidity score, coronary artery disease, congestive heart failure, peripheral vascular disease, stroke, diabetes mellitus, chronic obstructive pulmonary disease, cirrhosis, eGFR, acute kidney injury, ICU admission, the number of serum ionized calcium measurements, length of hospital stay, admission serum ionized calcium. 


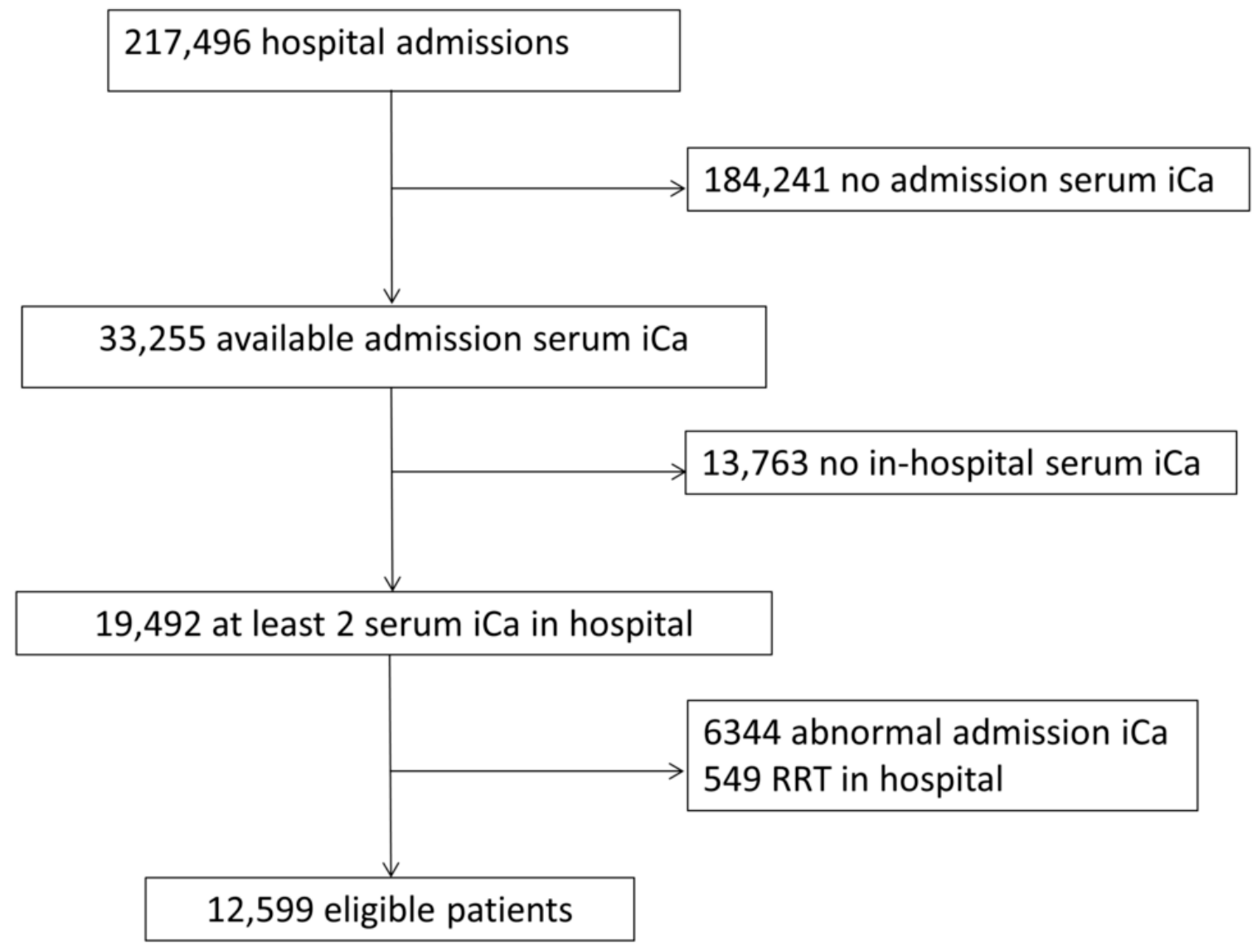

Figure 1. Study selection flow.

\section{Discussion}

Our study demonstrated that in-hospital serum ionized calcium derangements affected more than half of hospitalized patients (54\%). Hypocalcemia occurred more often than hypercalcemia in the hospital. Moreover, we demonstrated for the first time that serum calcium disturbances in hospitalized patients are both common and associated with higher mortality.

In-hospital hypocalcemia and hypercalcemia were significantly associated with higher in-hospital mortality compared with persistently normal serum ionized calcium levels throughout hospitalization. This finding is in line that in-hospital mortality progressively increased with greater total calcium level changes, either in a decremental or incremental direction [12]. Our studies support the significance of calcium level fluctuations toward mortality. Hypercalcemia in the hospitalized setting is commonly seen in patients with cancers or endocrine/metabolic disorders [3,13,21]. An increase in calcium levels can cause renal vasoconstriction and nephrogenic diabetes insipidus, resulting in volume depletion and leading to a pre-renal AKI or exacerbating its severity [4]. AKI has been clearly linked with worse patient outcomes, including hospital and long-term mortality [22-25]. In addition, hypercalcemia is associated with acute neuronal injury [26] and acute congestive heart failure [27].

It has been observed that hypocalcemia is highly prevalent in critically ill patients and is associated with the severity of illness [2]. The underlying pathophysiology of this finding is not entirely understood. Some evidence suggests that resistance to the effects of PTH in the kidney and bone is involved [28-30]. Proinflammatory cytokines, namely tumor necrosis factor- $\alpha$, have been linked to the severity of hypocalciuria and low concentrations of vitamin D metabolites in critically ill patients [29]. Moreover, hypomagnesemia, another common electrolyte complication in critically ill patients, could impair PTH secretion and thus has been suggested as a possible contributor to hypocalcemia $[31,32]$. Our study was adjusted for all possible confounders including comorbidities, 
and the association between in-hospital hypocalcemia and higher in-hospital mortality remains significant. Although the underlying mechanisms remain unclear, it is suggested that hypocalcemia can result in alteration of the myocardium action potential, leading to decreased cardiac contractility and acute pulmonary edema $[17,33,34]$.

Our study has several limitations. First, this is a retrospective study from a single center and predominantly consisted of Caucasian patients. Hence, the generalizability of our findings may be limited. In addition, our cohort of hospitalized patients is highly selected. Serum ionized calcium is normally monitored in more critically ill patients, as supported by the finding that $69 \%$ of our cohort had ICU admission, or patients at high risk of serum calcium derangement. Thus, the incidence of serum calcium derangement reported in this observational study might over-estimate the actual incidence in general hospitalized patients. Second, we did not have data on vitamin D, PTH, serum pH, diet, or medications that might alter serum ionized calcium levels (oral or intravenous calcium or vitamin $\mathrm{D}$ supplements, diuretics), as well as the causes and timing of in-hospital dyscalcemia. Therefore, there may be unmeasured or residual confounders to our analysis. Nevertheless, the strengths of our study are worth mentioning. Firstly, we included a large cohort of 13,148 adult patients hospitalized with multiple principal diagnoses, and we adjusted for several potential confounders. Second, we excluded patients who had abnormal admission serum ionized calcium levels. This allowed us to ensure that we were explicitly investigating the incidence of in-hospital serum ionized calcium derangements and their impact on in-hospital mortality.

\section{Conclusions}

In conclusion, in-hospital serum ionized calcium derangements affected more than half of the hospitalized patients. In-hospital hypocalcemia and hypercalcemia were both significantly associated with increased in-hospital mortality.

Author Contributions: Conceptualization, C.T., P.H., T.P., M.A.M., T.B., S.V., P.L., F.Q., S.B.E. and W.C.; Data curation, C.T.; Formal analysis, C.T.; Investigation, C.T., P.H., T.P. and W.C.; Methodology, C.T., T.P., M.A.M., T.B., S.V., F.Q., S.B.E. and W.C.; Project administration, T.B. and S.V.; Resources, C.T.; Software, C.T.; Supervision, M.A.M., S.V., F.Q., S.B.E. and W.C.; Validation, C.T., T.P., T.B., P.L. and W.C.; Visualization, C.T., T.P. and W.C.; Writing-original draft, C.T. and P.H.; Writing-review and editing, C.T., P.H., T.P., M.A.M., T.B., S.V., P.L., F.Q., S.B.E. and W.C. All authors have read and agreed to the published version of the manuscript.

Funding: This research received no specific grant from any funding agency in the public, commercial, or not-for-profit sectors.

Conflicts of Interest: The authors declare no conflict of interest.

\section{References}

1. Peacock, M. Calcium metabolism in health and disease. Clin. J. Am. Soc. Nephrol. 2010, 5 (Suppl. 1), S23-S30. [CrossRef] [PubMed]

2. Desai, T.K.; Carlson, R.W.; Geheb, M.A. Prevalence and clinical implications of hypocalcemia in acutely ill patients in a medical intensive care setting. Am. J. Med. 1988, 84, 209-214. [CrossRef]

3. Akirov, A.; Gorshtein, A.; Shraga-Slutzky, I.; Shimon, I. Calcium levels on admission and before discharge are associated with mortality risk in hospitalized patients. Endocrine 2017, 57, 344-351. [CrossRef] [PubMed]

4. Thongprayoon, C.; Cheungpasitporn, W.; Chewcharat, A.; Mao, M.A.; Bathini, T.; Vallabhajosyula, S.; Thirunavukkarasu, S.; Kashani, K.B. Impact of admission serum ionized calcium levels on risk of acute kidney injury in hospitalized patients. Sci. Rep. 2020, 10, 12316. [CrossRef]

5. Thongprayoon, C.; Cheungpasitporn, W.; Chewcharat, A.; Mao, M.A.; Kashani, K.B. Serum ionised calcium and the risk of acute respiratory failure in hospitalised patients: A single-centre cohort study in the USA. BMJ Open 2020, 10, e034325. [CrossRef]

6. Phillips, P.; Pain, R. Correcting the calcium. Br. Med. J. 1977, 1, 598. [CrossRef]

7. Gauci, C.; Moranne, O.; Fouqueray, B.; de la Faille, R.; Maruani, G.; Haymann, J.P.; Jacquot, C.; Boffa, J.J.; Flamant, M.; Rossert, J.; et al. Pitfalls of measuring total blood calcium in patients with CKD. J. Am. Soc. Nephrol. 2008, 19, 1592-1598. [CrossRef] 
8. Comorbid conditions and correlations with mortality risk among 3399 incident hemodialysis patients. Am. J. Kidney Dis. 1992, 20, 32-38.

9. Ladenson, J.H.; Lewis, J.W.; Boyd, J.C. Failure of total calcium corrected for protein, albumin, and $\mathrm{pH}$ to correctly assess free calcium status. J. Clin. Endocrinol. Metab. 1978, 46, 986-993. [CrossRef]

10. Oberleithner, H.; Greger, R.; Lang, F. The effect of respiratory and metabolic acid-base changes on ionized calcium concentration: In vivo and in vitro experiments in man and rat. Eur. J. Clin. Investig. 1982, 12, 451-455. [CrossRef]

11. Sauter, T.C.; Lindner, G.; Ahmad, S.S.; Leichtle, A.B.; Fiedler, G.M.; Exadaktylos, A.K.; Haider, D.G. Calcium Disorders in the Emergency Department: Independent Risk Factors for Mortality. PLoS ONE 2015, 10, e0132788. [CrossRef] [PubMed]

12. Thongprayoon, C.; Cheungpasitporn, W.; Hansrivijit, P.; Medaura, J.; Chewcharat, A.; Mao, M.A.; Bathini, T.; Vallabhajosyula, S.; Thirunavukkarasu, S.; Erickson, S.B. Impact of Changes in Serum Calcium Levels on In-Hospital Mortality. Medicina 2020, 56, 106. [CrossRef] [PubMed]

13. Cheungpasitporn, W.; Thongprayoon, C.; Mao, M.A.; Kittanamongkolchai, W.; Sakhuja, A.; Erickson, S.B. Impact of admission serum calcium levels on mortality in hospitalized patients. Endocr. Res. 2018, 43, 116-123. [CrossRef] [PubMed]

14. Yamaguchi, S.; Hamano, T.; Doi, Y.; Oka, T.; Kajimoto, S.; Kubota, K.; Yasuda, S.; Shimada, K.; Matsumoto, A.; Hashimoto, N.; et al. Hidden Hypocalcemia as a Risk Factor for Cardiovascular Events and All-Cause Mortality among Patients Undergoing Incident Hemodialysis. Sci. Rep. 2020, 10, 4418. [CrossRef] [PubMed]

15. Obi, Y.; Park, C.; Soohoo, M.; Sumida, K.; Hamano, T.; Rhee, C.M.; Kovesdy, C.P.; Kalantar-Zadeh, K.; Streja, E. Association of Pre-ESRD Serum Calcium With Post-ESRD Mortality Among Incident ESRD Patients: A Cohort Study. J. Bone Miner. Res. 2018, 33, 1027-1036. [CrossRef]

16. Inaguma, D.; Koide, S.; Takahashi, K.; Hayashi, H.; Hasegawa, M.; Yuzawa, Y.; Tanaka, A.; Murata, M.; Shinjo, H.; Otsuka, Y.; et al. Relationship between serum calcium level at dialysis initiation and subsequent prognosis. Renal Replace. Ther. 2017, 3, 2. [CrossRef]

17. Miura, S.; Yoshihisa, A.; Takiguchi, M.; Shimizu, T.; Nakamura, Y.; Yamauchi, H.; Iwaya, S.; Owada, T.; Miyata, M.; Abe, S.; et al. Association of Hypocalcemia With Mortality in Hospitalized Patients With Heart Failure and Chronic Kidney Disease. J. Card Fail. 2015, 21, 621-627. [CrossRef]

18. Lu, J.L.; Molnar, M.Z.; Ma, J.Z.; George, L.K.; Sumida, K.; Kalantar-Zadeh, K.; Kovesdy, C.P. Racial Differences in Association of Serum Calcium with Mortality and Incident Cardio- and Cerebrovascular Events. J. Clin. Endocrinol. Metab. 2016, 101, 4851-4859. [CrossRef]

19. Thongprayoon, C.; Cheungpasitporn, W.; Chewcharat, A.; Mao, M.A.; Thirunavukkarasu, S.; Kashani, K.B. Hospital mortality and long-term mortality among hospitalized patients with various admission serum ionized calcium levels. Postgrad. Med. 2020, 132, 385-390. [CrossRef]

20. Cheungpasitporn, W.; Thongprayoon, C.; Mao, M.A.; Kittanamongkolchai, W.; Sakhuja, A.; Erickson, S.B. Admission serum phosphate levels predict hospital mortality. Hosp. Pract. 2018, 46, 121-127. [CrossRef]

21. Wysolmerski, J.J.; Broadus, A.E. Hypercalcemia of malignancy: The central role of parathyroid hormone-related protein. Annu. Rev. Med. 1994, 45, 189-200. [CrossRef] [PubMed]

22. Thongprayoon, C.; Cheungpasitporn, W.; Mao, M.A.; Harrison, A.M.; Erickson, S.B. Elevated admission serum calcium phosphate product as an independent risk factor for acute kidney injury in hospitalized patients. Hosp. Pract. 2019, 47, 73-79. [CrossRef] [PubMed]

23. Thongprayoon, C.; Cheungpasitporn, W.; Mao, M.A.; Erickson, S.B. Calcium-phosphate product and its impact on mortality in hospitalized patients. Nephrology 2020, 25, 22-28. [CrossRef] [PubMed]

24. Thongprayoon, C.; Cheungpasitporn, W.; Mao, M.A.; Sakhuja, A.; Erickson, S.B. Admission calcium levels and risk of acute kidney injury in hospitalised patients. Int. J. Clin. Pract. 2018, 72, e13057. [CrossRef] [PubMed]

25. Baylis, P.H.; Milles, J.J.; Wilkinson, R.; Heath, D.A. Vasopressin function in hypercalcaemia. Clin. Endocrinol. 1981, 15, 343-351. [CrossRef] [PubMed]

26. Chung, J.W.; Ryu, W.S.; Kim, B.J.; Yoon, B.W. Elevated calcium after acute ischemic stroke: Association with a poor short-term outcome and long-term mortality. J. Stroke 2015, 17, 54-59. [CrossRef] [PubMed]

27. Lutsey, P.L.; Alonso, A.; Michos, E.D.; Loehr, L.R.; Astor, B.C.; Coresh, J.; Folsom, A.R. Serum magnesium, phosphorus, and calcium are associated with risk of incident heart failure: The Atherosclerosis Risk in Communities (ARIC) Study. Am. J. Clin. Nutr. 2014, 100, 756-764. [CrossRef] 
28. Nair, P.; Lee, P.; Reynolds, C.; Nguyen, N.D.; Myburgh, J.; Eisman, J.A.; Center, J.R. Significant perturbation of vitamin D-parathyroid-calcium axis and adverse clinical outcomes in critically ill patients. Intensive Care Med. 2013, 39, 267-274. [CrossRef]

29. Lind, L.; Carlstedt, F.; Rastad, J.; Stiernström, H.; Stridsberg, M.; Ljunggren, O.; Wide, L.; Larsson, A.; Hellman, P.; Ljunghall, S. Hypocalcemia and parathyroid hormone secretion in critically ill patients. Crit. Care Med. 2000, 28, 93-99. [CrossRef]

30. Zaloga, G.P.; Chernow, B. The multifactorial basis for hypocalcemia during sepsis. Studies of the parathyroid hormone-vitamin D axis. Ann. Intern. Med. 1987, 107, 36-41. [CrossRef]

31. Chernow, B.; Bamberger, S.; Stoiko, M.; Vadnais, M.; Mills, S.; Hoellerich, V.; Warshaw, A.L. Hypomagnesemia in patients in postoperative intensive care. Chest 1989, 95, 391-397. [CrossRef] [PubMed]

32. Hébert, P.; Mehta, N.; Wang, J.; Hindmarsh, T.; Jones, G.; Cardinal, P. Functional magnesium deficiency in critically ill patients identified using a magnesium-loading test. Crit. Care Med. 1997, 25, 749-755. [CrossRef] [PubMed]

33. Tse, G.; Chan, Y.W.; Keung, W.; Yan, B.P. Electrophysiological mechanisms of long and short QT syndromes. Int. J. Cardiol. Heart Vasc. 2017, 14, 8-13. [CrossRef] [PubMed]

34. Hurley, K.; Baggs, D. Hypocalcemic cardiac failure in the emergency department. J. Emerg. Med. 2005, 28, 155-159. [CrossRef] [PubMed]

Publisher's Note: MDPI stays neutral with regard to jurisdictional claims in published maps and institutional affiliations.

(C) 2020 by the authors. Licensee MDPI, Basel, Switzerland. This article is an open access article distributed under the terms and conditions of the Creative Commons Attribution (CC BY) license (http://creativecommons.org/licenses/by/4.0/). 